\title{
Treatment adherence and effect of concurrent statin intensity on the efficacy and safety of alirocumab in a real-life setting: results from ODYSSEY APPRISE
}

\author{
Maciej Banach¹, José Luis López-Sendon², Maurizio Averna ${ }^{3}$, Bertrand Cariou 4 , Megan Loy \\ Garen Manvelian' ${ }^{6}$, Isabela Batsu' ${ }^{5}$, Yann Poulouin7, Daniel Gaudet ${ }^{8}$, on behalf of the ODYSSEY \\ APPRISE study investigators
}

\author{
${ }^{1}$ Department of Preventive Cardiology and Lipidology, Medical University of Lodz \\ (MUL), Lodz, Poland \\ ${ }^{2}$ Hospital Universitario La Paz, IdiPaz, CIBER-CV, UAM, Madrid, Spain \\ ${ }^{3}$ Department of Health Promotion Sciences, Maternal and Infantile Care, Internal \\ Medicine and Medical Specialties - PROMISE, School of Medicine, University \\ of Palermo, Palermo, Italy \\ 4'institut du thorax, CHU Nantes, INSERM, CNRS, UNIV Nantes, Nantes, France \\ ${ }^{5}$ Sanofi, Bridgewater, NJ, United States \\ ${ }^{6}$ Regeneron Pharmaceuticals, Inc., Tarrytown, NY, United States \\ ${ }^{7}$ IT\&M Stats, Paris, France \\ ${ }^{8}$ ECOGENE-21 and Clinical Lipidology Unit, Community Gene Medicine Center, \\ Department of Medicine, Université de Montréal, Chicoutimi, QC, Canada
}

Submitted: 22 October 2021; Accepted: 29 October 2021

Online publication: 29 October 2021

Arch Med Sci 2022; 18 (2): 285-292

DOI: https://doi.org/10.5114/aoms/143476

Copyright (c) 2021 Termedia \& Banach

\begin{abstract}
Introduction: The phase IIIb open-label ODYSSEY APPRISE study prospectively assessed the safety and efficacy of alirocumab (a proprotein convertase subtilisin/kexin type 9 [PCSK9] inhibitor) in a real-life setting in high cardiovascular risk patients with heterozygous familial hypercholesterolemia or low-density lipoprotein cholesterol (LDL-C) not at goal despite maximally tolerated dose statins \pm other lipid-lowering therapies (NCT02476006). This post-hoc analysis assessed patient adherence to statins and alirocumab, plus alirocumab efficacy and safety, according to concomitant statin intensity and prior ezetimibe usage.

Material and methods: Patients received alirocumab 75 or $150 \mathrm{mg}$ (dose adjustment based on physician's judgment) every 2 weeks (for $\geq 3$ to $\leq 30$ months). Results: Of 994 enrolled and treated patients, 58.4\% received concomitant high-intensity statins, $18.2 \%$ received moderate/low-intensity statins, and $23.4 \%$ received no statin; $55.9 \%$ received prior ezetimibe. Mean alirocumab adherence (percent adherence defined as injections received/theoretical injections $\times 100$ ) was $96.6 \%$ over 72.4 weeks' mean treatment duration. Mean LDL-C reduction from baseline at Week 12 was similar between statin intensity subgroups (53.6-55.7\%). More patients achieved LDL-C $<1.8 \mathrm{mmol} / \mathrm{l}$ and/ or $\geq 50 \%$ reduction from baseline in the $\geq 100 \%$ versus $<100 \%$ adherent to alirocumab subgroup; high-intensity and low/moderate-intensity subgroups versus no statin subgroup; and prior ezetimibe versus no prior ezetimibe subgroup. Treatment-emergent adverse events occurred in $65.2-75.1 \%$ and $68.0-76.3 \%$ of patients across statin and ezetimibe subgroups, respectively. Conclusions: In a real-life setting, patient adherence to alirocumab was high. Alirocumab provided clinically significant reductions in LDL-C, with most patients achieving LDL-C treatment targets across background statin therapy and prior ezetimibe therapy subgroups.
\end{abstract}

Key words: cholesterol, low-density lipoprotein, PCSK9, treatment adherence.

\author{
Corresponding author: \\ Maciej Banach MD, PhD \\ Department of Preventive \\ Cardiology and Lipidology \\ Medical University of Lodz \\ Lodz, Poland \\ Phone: +48 426482005 \\ E-mail: \\ maciej.banach@umed.lodz.pl
}




\section{Introduction}

Hypercholesterolemia is a significant risk factor for the development of atherosclerosis and coronary heart disease $[1,2]$, a leading cause of mortality worldwide [3-5]. The management of severe hypercholesterolemia involves the modification of cardiovascular (CV) risk factors and the use of lipid-lowering therapies (LLTs) [1, 2, 6]. In clinical practice, many patients with hypercholesterolemia at high or very-high CV risk do not reach their low-density lipoprotein cholesterol (LDL-C) treatment goals, remaining at high risk of atherosclerotic CV disease (ASCVD) [7-11].

There are multiple factors leading to patients with hypercholesterolemia not achieving their CV risk-based LDL-C goals. Achievement of LDL-C goals can be limited by poor adherence to LLTs [12]. In addition, statin intolerance is an issue for some patients [13-15], and discontinuation of statin therapy may cause an increase in CV events [16]. Recent European and American guidelines recommend considering the addition of a proprotein convertase subtilisin/kexin type 9 (PCSK9) inhibitor for patients at very-high CV risk not achieving their risk-based LDL-C goal, or for adult patients with heterozygous familial hypercholesterolemia $(\mathrm{HeFH})$ and $\mathrm{LDL}-\mathrm{C} \geq 2.6 \mathrm{mmol} / \mathrm{l}$ $(100 \mathrm{mg} / \mathrm{dl})$, while receiving maximally tolerated statin and ezetimibe [1, 2].

The aim of this post hoc analysis was to examine: 1) patient adherence to treatment, and 2) the efficacy and 3) safety of alirocumab according to background statin therapy and prior ezetimibe medication in high CV risk patients with hypercholesterolemia, using data from the ODYSSEY APPRISE study.

\section{Material and methods}

\section{Study design}

The single-arm, phase IIIb, open-label ODYSSEY APPRISE study (NCT02476006) was designed with the objective of assessing the safety and efficacy of alirocumab, a PCSK9 inhibitor, in a real-life setting among high CV risk patients with severe hypercholesterolemia inadequately controlled with maximally tolerated statin \pm other LLTs (excluding PCSK9 inhibitors) [17]. The study provided patients with severe hypercholesterolemia access to alirocumab ahead of commercial avialability in Canada and 16 European countries. Despite ODYSSEY APPRISE oversight, including the necessary monitoring of patients, the open-label design provided a setting similar to real-life compared with randomized controlled trials. The ODYSSEY APPRISE study design has been reported previously [17]. Briefly, patients aged $\geq 18$ years at high CV risk with severe hy- percholesterolemia not adequately controlled by maximally tolerated dose statins \pm other LLTs were eligible to enroll in ODYSSEY APPRISE (full inclusion criteria, as well as details of cardiovascular risk groups at inclusion, can be found in Supplementary Table SI). Following a screening period of up to 3 weeks, patients received subcutaneous alirocumab $75 \mathrm{mg}$ or $150 \mathrm{mg}$ every 2 weeks (Q2W) for an open-label treatment duration of $\geq 12$ weeks to $\leq 30$ months. The alirocumab dose could be adjusted from 75 to $150 \mathrm{mg}$ Q2W, or vice versa, based on the physician's judgment and treatment response. Alirocumab was administered on top of background stable maximally tolerated dose statins \pm other LLTs.

The ODYSSEY APPRISE study was conducted in accordance with the Declaration of Helsinki and the International Conference on Harmonization Guidelines for Good Clinical Practice. The study protocol was approved by the appropriate institutional review boards or independent ethics committee at each study center. Written informed consent was obtained from all participating individuals prior to their involvement in study-related activities.

\section{Endpoints and assessments}

The primary endpoint of ODYSSEY APPRISE was to assess safety parameters throughout the study, including treatment-emergent adverse events (TEAEs), laboratory data, product complaints, and vital signs. The main secondary efficacy endpoint was the percent change in calculated LDL-C from baseline to Week 12 . Key secondary efficacy endpoints assessed at Week 12 included the proportion of patients achieving calculated LDL-C $<2.6 \mathrm{mmol} / \mathrm{l}(100 \mathrm{mg} / \mathrm{dl})$, calculated LDL-C $<1.8 \mathrm{mmol} / \mathrm{l}(70 \mathrm{mg} / \mathrm{dl})$, or calculated LDL-C $<1.8 \mathrm{mmol} / \mathrm{l}(70 \mathrm{mg} / \mathrm{dl})$ and/or $\geq 50 \%$ reduction from baseline (if LDL-C $\geq 1.8 \mathrm{mmol} / \mathrm{l}[70 \mathrm{mg} / \mathrm{dl}]$ ).

Adherence to alirocumab treatment was assessed according to patients' diary data over the duration of the trial; percent adherence was defined as the number of injections received divided by the number of theoretical injections to be received during the study period multiplied by 100 , with the number of theoretical injections defined as the last injection date minus the first injection date divided by 14 .

LDL-C was calculated using the Friedewald formula [18] at all analysis time points; however, if triglyceride values were $>400 \mathrm{mg} / \mathrm{dl}$ then the LDL-C values were excluded from the current analyses. As the ODYSSEY APPRISE trial was initiated in 2015, the Friedewald formula was an accepted method for calculating LDL-C values at this time and was routinely used across other clinical trials of the ODYSSEY phase III program. 


\section{Statistical analysis}

The safety population included all patients who received at least one dose or partial dose of alirocumab. Safety outcomes were analyzed by descriptive statistics for the total population and according to background statin therapy.

Efficacy analyses were performed on the modified intention-to-treat (mITT) population, which included all patients who had received at least one dose or partial dose of alirocumab, had baseline LDL-C data available, and had at least one LDL-C measurement within the analysis window associated with Week 12. Efficacy endpoints were also analyzed by descriptive statistics for both the overall population and according to background statin therapy.

Adherence to treatment was described as the mean (standard deviation [SD]) percent adherence over the duration of the trial. The mean reduction in LDL-C from baseline was assessed according to treatment adherence over the duration of the trial in patients with treatment adherence $\geq 100 \%$ and $<100 \%$.

\section{Results}

A total of 994 patients were enrolled and treated: 580 (58.4\%) were receiving background high-intensity statins, 181 (18.2\%) were receiving background low/moderate-intensity statins, and 233 (23.4\%) were receiving no statins. In ad- dition, 556 (55.9\%) patients had received prior ezetimibe, which ranged from $66.0 \%$ of patients in the high-intensity statin subgroup to $30.5 \%$ of patients in the no statin subgroup (Table I). Baseline characteristics for the overall population and according to background statin therapy are shown in Table I. Patients in the no statin subgroup tended to be older, less likely to have $\mathrm{HeFH}$, and have higher baseline LDL-C compared with the other statin subgroups. Baseline characteristics according to prior ezetimibe medication are shown in Table II. Similar to the analysis by statin subgroup, patients in the no prior ezetimibe group were less likely to have $\mathrm{HeFH}$ and more likely to have higher baseline LDL-C compared with the prior ezetimibe group.

\section{Patient adherence to treatment}

Patients received alirocumab for a mean (SD) duration of $72.4( \pm 42.5)$ weeks. During the trial, $17.4 \%(n=160)$ of patients had a temporary treatment interruption of one or more doses (one or more scheduled alirocumab injections that were not administered as decided by the physician) and $4.5 \%(n=41)$ of patients permanently discontinued alirocumab treatment. The reasons for alirocumab treatment interruption included adverse events (28 patients) or other unspecified reasons (129 patients). No patients discontinued alirocumab due to very-low ( $<0.6 \mathrm{mmol} / \mathrm{l}[25 \mathrm{mg} / \mathrm{dl}]) \mathrm{LDL}-\mathrm{C}$ levels. While receiving treatment, mean (SD) overall adherence to alirocumab was $96.6 \%$ (11.1\%);

Table I. Baseline characteristics, both overall and according to background statin therapy* (safety population)

\begin{tabular}{|lcccc|}
\hline Parameter & $\begin{array}{c}\text { High-intensity } \\
\text { statin }(n=580)\end{array}$ & $\begin{array}{c}\text { Low/moderate- } \\
\text { intensity statin } \\
(n=181)\end{array}$ & No statin $(n=233)$ & All $(n=994)$ \\
\hline Age [years] mean (SD) & $55.2(11.6)$ & $55.3(12.3)$ & $61.3(10.4)$ & $56.6(11.7)$ \\
\hline Male, $n(\%)$ & $370(63.8)$ & $112(61.9)$ & $143(61.4)$ & $625(62.9)$ \\
\hline BMI $\left[\mathrm{kg} / \mathrm{m}^{2}\right]$ mean (SD) & $28.4(5.1)$ & $27.6(4.7)$ & $27.3(4.4)$ & $28.0(4.9)$ \\
\hline HeFH, $n(\%)$ & $436(75.2)$ & $119(65.7)$ & $81(34.8)$ & $636(64.0)$ \\
\hline LDL-C $[$ mmol/l] mean (SD) & $4.5(1.4)$ & $4.8(1.4)$ & $5.2(1.9)$ & $4.8(1.6)$ \\
\hline Prior ezetimibe, $n(\%)$ & $383(66.0)$ & $102(56.4)$ & $71(30.5)$ & $556(55.9)$ \\
\hline
\end{tabular}

${ }^{*}$ High-intensity statin was defined as atorvastatin 40 or $80 \mathrm{mg}$, rosuvastatin 20 or $40 \mathrm{mg}$, or simvastatin $80 \mathrm{mg}$ daily; low/moderateintensity statin was defined as all other statins and/or doses. BMI-body mass index, HeFH - heterozygous familial hypercholesterolemia, $L D L-C$ - low-density lipoprotein cholesterol, SD - standard deviation.

Table II. Baseline characteristics, both overall and according to prior ezetimibe medication (safety population)

\begin{tabular}{|lccc|}
\hline Parameter & Prior ezetimibe $(n=556)$ & No ezetimibe $(n=438)$ & All $(n=994)$ \\
\hline Age $[$ years] mean (SD) & $56.2(11.6)$ & $57.1(11.9)$ & $56.6(11.7)$ \\
\hline Male, $n(\%)$ & $355(63.8)$ & $270(61.6)$ & $625(62.9)$ \\
\hline BMI $\left[\mathrm{kg} / \mathrm{m}^{2}\right.$ ] mean (SD) & $28.4(4.7)$ & $27.5(5.1)$ & $28.0(4.9)$ \\
\hline HeFH, $n(\%)$ & $417(75.0)$ & $219(50.0)$ & $636(64.0)$ \\
\hline LDL-C $[\mathrm{mmol} / \mathrm{l}]$ mean (SD) & $4.6(1.4)$ & $4.9(1.7)$ & $4.7(1.6)$ \\
\hline
\end{tabular}

$B M I$ - body mass index, HeFH - heterozygous familial hypercholesterolemia, LDL-C - low-density lipoprotein cholesterol, SD - standard deviation. 
$328(36 \%)$ patients were $<100 \%$ adherent and $593(64 \%)$ patients were $\geq 100 \%$ adherent, with 91 (10\%) patients having > 100\% adherence to alirocumab (for example, possibly due to receiving an alirocumab dose earlier than the 14-day dosing window). Mean alirocumab adherence was similar across different subgroups based on CV risk groups at inclusion, as well as by familial hypercholesterolemia (FH) status, and was also similar across background statin therapy subgroups and prior ezetimibe subgroups (Table III).

A total of 712 (77.3\%) patients were receiving concomitant statins at baseline (mITT analysis);
126 (17.7\%) patients either temporarily or permanently discontinued at least one statin during the study. As noted for alirocumab treatment above, the proportion of patients discontinuing statins was similar across different subgroups based on $\mathrm{CV}$ risk groups at inclusion (14.4-18.7\%) or by $\mathrm{FH}$ status $(17.6 \%$ for HeFH vs. $18.0 \%$ for non-FH).

\section{Efficacy}

Overall, mean ( \pm SD) LDL-C decreased by $2.6( \pm 1.2) \mathrm{mmol} / \mathrm{l}(98.6( \pm 46.30 \mathrm{mg} / \mathrm{dl})$ from baseline to Week 12 , with a mean $( \pm \mathrm{SD})$ percent reduction in LDL-C of $54.8 \%( \pm 20.0 \%)$. The mean

Table III. Alirocumab adherence* according to CV risk groups at inclusion, FH status, background statin intensity, and prior ezetimibe medication (safety population)

\begin{tabular}{|c|c|c|c|c|c|}
\hline \multirow[t]{2}{*}{ Variable } & \multicolumn{5}{|c|}{$\mathrm{CV}$ risk group at inclusion } \\
\hline & $\begin{array}{c}\text { A } \\
(n=354)\end{array}$ & $\begin{array}{c}\text { B } \\
(n=272)\end{array}$ & $\begin{array}{c}C \\
(n=294)\end{array}$ & $\begin{array}{c}\mathrm{D} \\
(n=226)\end{array}$ & $\begin{array}{c}\mathrm{E} \\
(n=224)\end{array}$ \\
\hline \multirow[t]{3}{*}{ Adherence, mean (SD), \% } & $97.5(9.2)$ & $97.9(9.3)$ & $98.2(8.2)$ & $94.5(15.3)$ & $95.8(10.5)$ \\
\hline & \multicolumn{5}{|c|}{ FH status } \\
\hline & \multicolumn{2}{|c|}{$\begin{array}{c}\text { HeFH } \\
(n=636)\end{array}$} & & \multicolumn{2}{|c|}{$\begin{array}{l}\text { Non-FH } \\
(n=358)\end{array}$} \\
\hline \multirow[t]{3}{*}{ Adherence, mean (SD), \% } & \multicolumn{2}{|c|}{$97.6(9.1)$} & & \multicolumn{2}{|c|}{$94.9(13.9)$} \\
\hline & \multicolumn{5}{|c|}{ Background statin intensity } \\
\hline & $\begin{array}{r}\text { Hig } \\
(n=5\end{array}$ & & $\begin{array}{l}\text { Low } / \text { modera } \\
\qquad(n=181)\end{array}$ & & $\begin{array}{l}\text { No statin } \\
(n=233)\end{array}$ \\
\hline \multirow[t]{3}{*}{ Adherence, mean (SD), \% } & $97.2(1$ & & $96.5(12.4)$ & & $95.4(12.4)$ \\
\hline & \multicolumn{5}{|c|}{ Prior ezetimibe medication } \\
\hline & \multicolumn{2}{|c|}{$\begin{array}{l}\text { Prior ezetimibe } \\
\quad(n=556)\end{array}$} & & \multicolumn{2}{|c|}{$\begin{array}{l}\text { No ezetimibe } \\
(n=438)\end{array}$} \\
\hline Adherence, mean (SD), \% & \multicolumn{2}{|c|}{$97.2(10.3)$} & & \multicolumn{2}{|c|}{$95.9(12.1)$} \\
\hline
\end{tabular}

*Adherence to alirocumab treatment was assessed according to patients' diary data over the duration of the trial; percent adherence was defined as the number of injections received divided by the number of theoretical injections to be received during the study period multiplied by 100, with the number of theoretical injections defined as the last injection date minus the first injection date divided by 14. CV-cardiovascular, FH - familial hypercholesterolemia, HeFH - heterozygous familial hypercholesterolemia, SD - standard deviation.

Table IV. Change from baseline in LDL-C at Weeks 12, 24, and 48 according to adherence to alirocumab* (mITT population)

\begin{tabular}{|c|c|c|}
\hline Mean (SD) & Adherence $<100 \%(n=328)$ & Adherence $\geq 100 \%(n=593)$ \\
\hline \multicolumn{3}{|l|}{ Baseline: } \\
\hline LDL-C [mmol/l] & $4.8(1.6)$ & $4.7(1.5)$ \\
\hline \multicolumn{3}{|l|}{ Week 12: } \\
\hline Change in LDL-C from baseline [mmol/l] & $-2.4(1.2)$ & $-2.6(1.2)$ \\
\hline Change in LDL-C from baseline (\%) & $-52.4(22.0)$ & $-56.1(18.8)$ \\
\hline \multicolumn{3}{|l|}{ Week 24: } \\
\hline Change in LDL-C from baseline [mmol/l] & $-2.5(1.3)$ & $-2.6(1.2)$ \\
\hline Change in LDL-C from baseline (\%) & $-51.4(23.9)$ & $-55.8(20.2)$ \\
\hline \multicolumn{3}{|l|}{ Week 48: } \\
\hline Change in LDL-C from baseline [mmol/l] & $-2.5(1.4)$ & $-2.6(1.4)$ \\
\hline Change in LDL-C from baseline (\%) & $-52.5(23.6)$ & $-55.6(23.5)$ \\
\hline
\end{tabular}

*Adherence to alirocumab treatment was assessed according to patients' diary data over the duration of the trial; percent adherence was defined as the number of injections received divided by the number of theoretical injections to be received during the study period multiplied by 100, with the number of theoretical injections defined as the last injection date minus the first injection date divided by 14. LDL-C - low-density lipoprotein cholesterol, mITT - modified intention-to-treat, SD - standard deviation. 
reduction in LDL-C from baseline was greater in the subgroup of patients who were $\geq 100 \%$ adherent to alirocumab compared with the subgroup of those who were $<100 \%$ adherent to alirocumab at Week 12 ( $-56.1 \%$ vs. $-52.4 \%)$, Week $24(-55.8 \%$ vs. $-51.4 \%)$, and Week 48 ( $-55.6 \%$ vs. $-52.5 \%$; Table IV). When analyzed by subgroups according to background statin therapy, the mean LDL-C reduction from baseline to Week 12 was similar between statin therapy subgroups, ranging from $53.6 \%$ to $55.7 \%$ (Table V).

A higher proportion of patients who were $\geq 100 \%$ adherent to alirocumab treatment achieved LDL-C goals of $<2.6 \mathrm{mmol} / \mathrm{l}(100 \mathrm{mg} / \mathrm{dl})$, $<1.8 \mathrm{mmol} / \mathrm{l}(70 \mathrm{mg} / \mathrm{dl})$, and $<1.8 \mathrm{mmol} / \mathrm{l}$ (70 $\mathrm{mg} / \mathrm{dl})$ and/or $\geq 50 \%$ reduction from base- line, at Weeks 12 and 24 compared with patients who were $<100 \%$ adherent to alirocumab (Figures $1 \mathrm{~A}, 2)$. At Week 12, a higher proportion of patients achieved LDL-C goals of $<2.6 \mathrm{mmol} / \mathrm{l}(100 \mathrm{mg} / \mathrm{dl})$ and $<1.8 \mathrm{mmol} / \mathrm{l}(70 \mathrm{mg} / \mathrm{dl})$ in the high-intensity and low/moderate-intensity subgroups compared with the no statin subgroup (Figure $1 \mathrm{~B}$ ). The attainment of LDL-C $<1.8 \mathrm{mmol} / \mathrm{l}(70 \mathrm{mg} / \mathrm{dl})$ and/or $\geq 50 \%$ reduction from baseline was similar across all background statin therapy subgroups (66.8$70.5 \%)$. Similarly, a higher proportion of patients who received prior ezetimibe medication achieved LDL-C goals at Week 12 compared with patients receiving no prior ezetimibe medication (Figure $1 \mathrm{C}$ ), which was also observed at Weeks 24 and 48 (Figure 3).

Table V. Change from baseline in LDL-C at Week 12, both overall and according to background statin therapy* (mITT population)

\begin{tabular}{|lcccc|}
\hline Mean (SD) & $\begin{array}{c}\text { High-intensity } \\
\text { statin }(n=543)\end{array}$ & $\begin{array}{c}\text { Low/moderate- } \\
\text { intensity stati } \\
(n=170)\end{array}$ & $\begin{array}{c}\text { No statin } \\
(n=208)\end{array}$ & All $(n=921)$ \\
\hline $\begin{array}{l}\text { Change in LDL-C from baseline } \\
\text { to Week 12 [mmol/l] }\end{array}$ & $-2.8(1.2)$ & $-2.6(1.3)$ & $-2.7(1.1)$ & $-2.5(1.2)$ \\
\hline $\begin{array}{l}\text { Percent change in LDL-C from } \\
\text { baseline to Week 12 (\%) }\end{array}$ & $-55.1(21.2)$ & $-55.7(21.2)$ & $-53.6(15.6)$ & $-54.8(20.0)$ \\
\hline
\end{tabular}

${ }^{*}$ High-intensity statin was defined as atorvastatin 40 or $80 \mathrm{mg}$, rosuvastatin 20 or $40 \mathrm{mg}$, or simvastatin $80 \mathrm{mg}$ daily; low/moderateintensity statin was defined as all other statins and/or doses. LDL-C - low-density lipoprotein cholesterol, mITT - modified intention-totreat, SD - standard deviation.

A

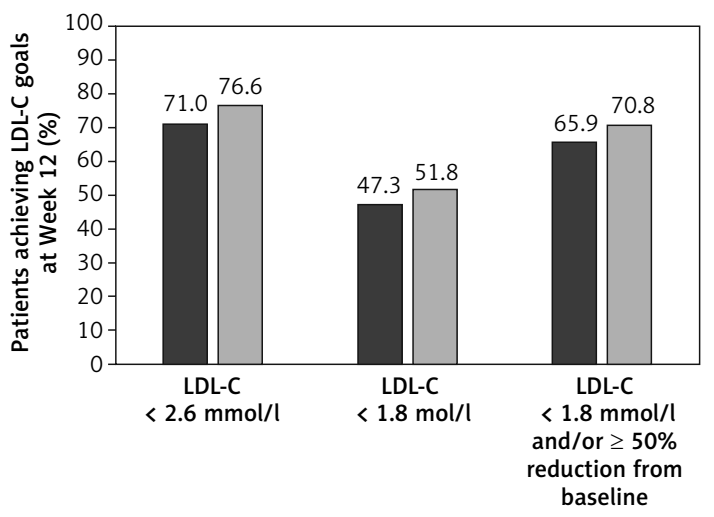

Adherence $<100 \%(n=328)$

$\square$ Adherence $\geq 100 \%(n=593)$

C

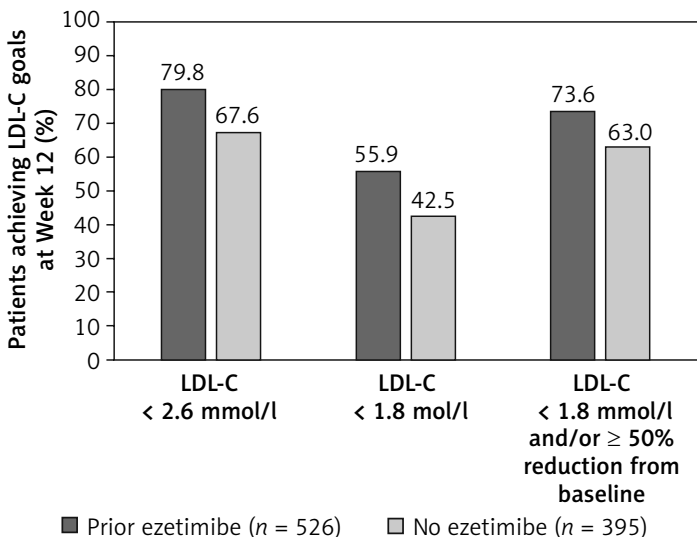

B

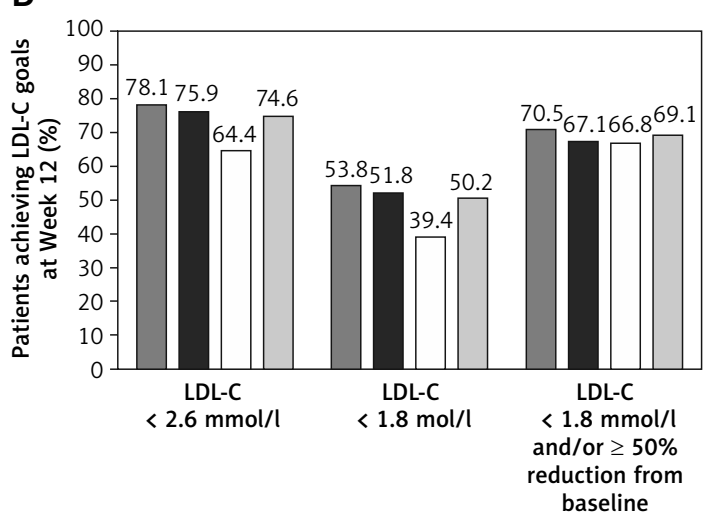

$\square$ High-intensity statin $(n=543)$

Low/moderate-intensity statin $(n=170)$

$\square$ No statin $(n=208) \quad \square$ Overall $(n=921)$

Figure 1. Proportion of patients achieving LDL-C goals at Week 12 on alirocumab treatment. A - According to adherence to alirocumab. B - Both overall and according to background statin intensity*. C - According to prior ezetimibe medication (mITT population

*High-intensity statin was defined as atorvastatin 40 or $80 \mathrm{mg}$, rosuvastatin 20 or $40 \mathrm{mg}$, or simvastatin $80 \mathrm{mg}$ daily; low/moderate-intensity statin was defined as all other statins and/or doses. LDL-C - low-density lipoprotein cholesterol, mITT - modified intention-totreat. 
A

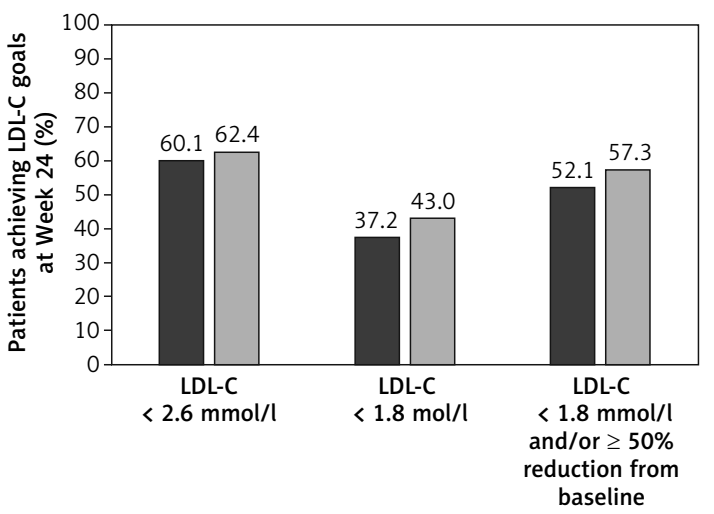

$\square$ Adherence $<100 \%(n=328)$

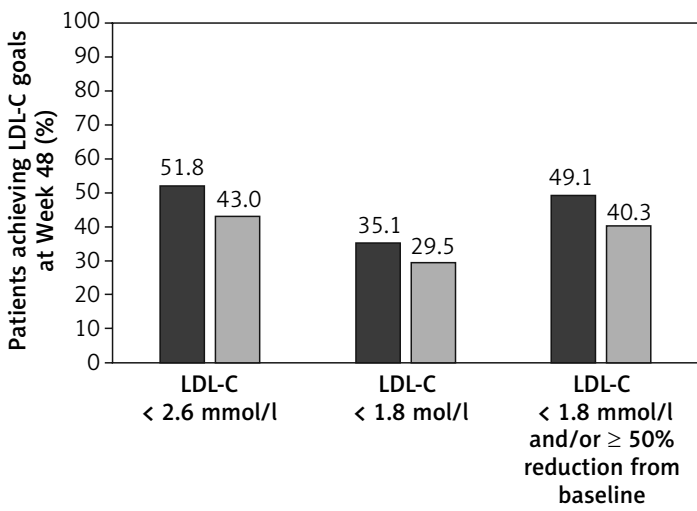

$\square$ Adherence $<100 \%(n=328)$

$\square$ Adherence $\geq 100 \%(n=593)$

Figure 2. Proportion of patients achieving LDL-C goals. A - Week 24. B - Week 48, according to adherence to alirocumab* (mITT population)

${ }^{*}$ Adherence to alirocumab treatment was assessed according to patients' diary data over the duration of the trial; percent adherence was defined as the number of injections received divided by the number of theoretical injections to be received during the study period multiplied by 100, with the number of theoretical injections defined as the last injection date minus the first injection date divided by 14. LDL-C - low-density lipoprotein cholesterol, mITT-modified intention-to-treat.

A

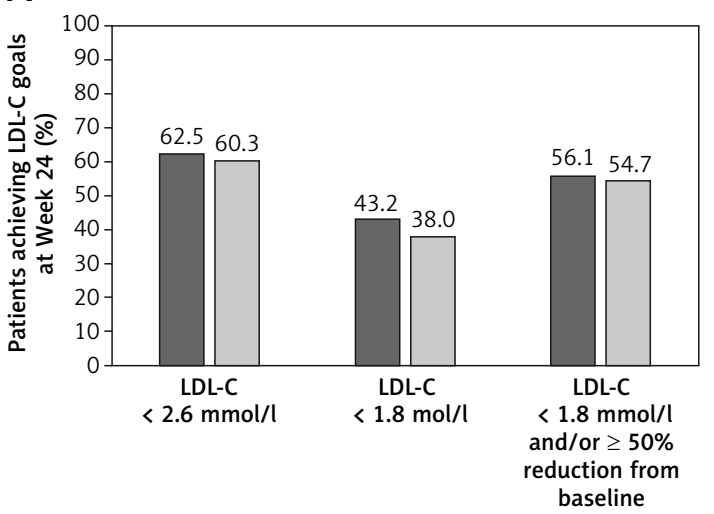

Prior ezetimibe $(n=526)$

$\square$ No ezetimibe $(n=395)$
B

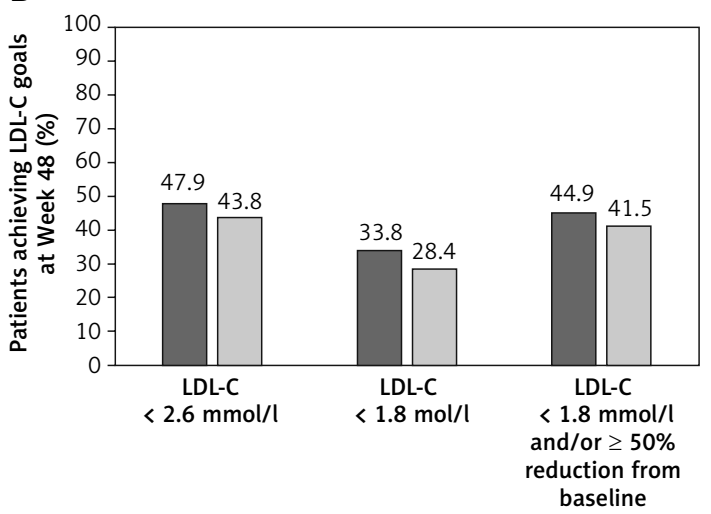

Prior ezetimibe $(n=526) \quad \square$ No ezetimibe $(n=395)$

Figure 3. Proportion of patients achieving LDL-C goals. A - Week 24. B - Week 48, according to prior ezetimibe medication (mITT population)

LDL-C - low-density lipoprotein cholesterol, mITT - modified intention-to-treat.

Table VI. Overview of TEAEs, both overall and according to background statin therapy* (safety population) $n$ (\%)

\begin{tabular}{|lcccc|}
\hline Parameter & $\begin{array}{c}\text { High-intensity } \\
\text { statin }(n=580)\end{array}$ & $\begin{array}{c}\text { Low/moderate- } \\
\text { intensity statin } \\
(n=181)\end{array}$ & $\begin{array}{l}\text { No statin } \\
(n=233)\end{array}$ & All $(n=994)$ \\
\hline Any TEAE & $378(65.2)$ & $136(75.1)$ & $198(85.0)$ & $712(71.6)$ \\
\hline Treatment-emergent SAEs & $85(14.7)$ & $21(11.6)$ & $55(23.6)$ & $161(16.2)$ \\
\hline TEAEs leading to death & $1(0.2)$ & $1(0.6)$ & $21(9.0)$ & $2(0.2)$ \\
\hline $\begin{array}{l}\text { TEAEs leading to permanent } \\
\text { treatment discontinuation }\end{array}$ & $16(2.8)$ & $8(4.4)$ & $45(4.5)$ \\
\hline
\end{tabular}

*High-intensity statin was defined as atorvastatin 40 or $80 \mathrm{mg}$, rosuvastatin 20 or $40 \mathrm{mg}$, or simvastatin $80 \mathrm{mg}$ daily; low/moderateintensity statin was defined as all other statins and/or doses. SAE - serious adverse event, TEAE - treatment-emergent adverse event.

\section{Safety}

The safety of alirocumab during ODYSSEY APPRISE has been previously reported for the overall study population [17]. TEAEs according to background statin therapy are summarized in Table VI, with a detailed list provided in Supplementary Ta- ble SII. TEAEs were reported in $65.2 \%, 75.1 \%$, and $85.0 \%$ of patients in the high-intensity, low/moderate-intensity, and no statin subgroups, respectively. Furthermore, TEAEs were reported in $68.0 \%$ versus $76.3 \%$ of patients receiving prior ezetimibe versus no prior ezetimibe (Supplementary Table SIII). 


\section{Discussion}

This post-hoc analysis of the ODYSSEY APPRISE study examined patient adherence to treatment, as well as the efficacy and safety of alirocumab according to background statin therapy and prior ezetimibe medication, in patients with severe hypercholesterolemia at high or very-high risk of future CV events. The results of this study are of large importance in light of the large volume of epidemiological data recently published, suggesting inadequate cholesterol-lowering efficacy over the last few decades, with nonadherence being one of the most important reasons $[4,19]$.

The effectiveness of LLTs is influenced by a patient's adherence to their treatment regimen [20]. Non-adherence to LLTs has been associated with adverse outcomes in patients with ASCVD [21], and it is suggested that strategies that improve adherence, as well as greater use of intensive LLTs, substantially improve CV risk [22]. In the present ODYSSEY APPRISE trial, adherence to alirocumab was high (96.6\%) over a mean treatment duration of 72.4 weeks. This high rate of adherence to alirocumab compares with that observed for patients with HeFH during the open-label ODYSSEY OLE study [23].

Adherence to background statin therapy was also high, with only $17.7 \%$ of patients discontinuing statin therapy, either permanently or temporarily, during the trial. In contrast, a population-based study demonstrated that, even in patients who have experienced a CV event, adherence to statin therapy was low [24]. This may reflect differences in treatment adherence between clinical trials and everyday clinical practice. Overall, the reduction in LDL-C and the proportion of patients achieving LDL-C treatment goals were similar across all background statin therapy subgroups (66.8-70.5\%). The high rate of patient adherence to both background statin therapy and alirocumab translates to a high proportion of patients meeting LDL-C goals in this analysis of ODYSSEY APPRISE.

It should be noted that, although a high rate of adherence was observed for both background statin therapy and alirocumab in this study, statins are a continuing LLT whereas alirocumab is a newly initiated LLT during ODYSSEY APPRISE. This makes the high adherence to alirocumab even more remarkable, as new medications typically have a lower rate of adherence compared with existing, tolerated medications. However, it has been observed that patients who adhere to one treatment are more likely to adhere to other aspects of a healthy lifestyle, for example the high adherence to both the background statin and/or ezetimibe medication and alirocumab observed in this analysis [25].
Additionally, in this analysis, the overall incidence of TEAEs according to higher background statin intensity or prior ezetimibe therapy was not higher than that observed in the overall population [17]. Furthermore, for patients receiving high-intensity statins or prior ezetimibe therapy, the incidence of TEAEs leading to treatment discontinuation was not higher than that observed in the overall population. This complements the results of a previous pooled analysis of phase II and phase III studies including patients receiving concomitant statins at the maximally tolerated dose, which showed that alirocumab treatment was not associated with any increase in musculoskeletal events [26].

Limitations of this analysis include the lack of a comparative control and the possible introduction of bias due to the open-label study design. In addition, the lack of detailed information on the reasons for alirocumab discontinuation (defined as unspecified), are a limitation to the interpretation of the current analyses.

In conclusion, patient adherence to alirocumab treatment was found to be high. In addition, alirocumab provided clinically significant reductions in LDL-C and enabled the majority of patients to achieve their LDL-C treatment targets irrespective of background statin therapy.

\section{Acknowledgments}

The authors would like to thank the patients, their families, and all investigators involved in this study. Medical writing and editorial support, under the direction of the authors, was provided by Rachel Dunn, PhD, of Prime, Knutsford, UK, funded by Sanofi according to Good Publication Practice guidelines. The sponsor was involved in the study design and collection, analysis, and interpretation of data, as well as data checking of information provided in the manuscript. The authors had unrestricted access to study data, were responsible for all content and editorial decisions, and received no honoraria related to the development of this manuscript.

\section{Financial support}

The ODYSSEY APPRISE study was supported by Sanofi and Regeneron Pharmaceuticals, Inc.

\section{Data sharing}

Qualified researchers may request access to patient-level data and related study documents, including the clinical study report, study protocol with any amendments, blank case report from, statistical analysis plan, and data set specifications. Patient-level data will be anonymized, and study documents will be redacted to protect the 
privacy of trial participants. Further details on Sanofi's data sharing criteria, eligible studies, and process for requesting access can be found at https://www.clinicalstudy datarequest.com.

\section{References}

1. Mach F, Baigent C, Catapano AL, et al. 2019 ESC/EAS guidelines for the management of dyslipidaemias: lipid modification to reduce cardiovascular risk. Eur Heart J 2020; 41: 111-88.

2. Grundy SM, Stone NJ, Bailey AL, et al. 2018 AHA/ACC/ AACVPR/AAPA/ABC/ACPM/ADA/AGS/APhA/ASPC/NLA/ PCNA Guideline on the Management of Blood Cholesterol: Executive Summary: A Report of the American College of Cardiology/American Heart Association Task Force on Clinical Practice Guidelines. J Am Coll Cardiol 2019; 73: 3168-209.

3. Benjamin EJ, Muntner P, Alonso A, et al. Heart disease and stroke statistics - 2019 update: A report from the American Heart Association. Circulation 2019; 139: e56-528.

4. NCD Risk Factor Collaboration. National trends in total cholesterol obscure heterogeneous changes in HDL and non-HDL cholesterol and total-to-HDL cholesterol ratio: a pooled analysis of 458 population-based studies in Asian and Western countries. Int J Epidemiol 2019; 49: 173-92.

5. GBD 2017 Causes of Death Collaborators. Global, regional, and national age-sex-specific mortality for 282 causes of death in 195 countries and territories, 19802017: a systematic analysis for the Global Burden of Disease Study 2017. Lancet 2018; 392: 1736-88.

6. Booth JN $3^{\text {rd }}$, Colantonio LD, Howard G, et al. Healthy lifestyle factors and incident heart disease and mortality in candidates for primary prevention with statin therapy. Int J Cardiol 2016; 207: 196-202.

7. Huijgen R, Kindt I, Verhoeven SB, et al. Two years after molecular diagnosis of familial hypercholesterolemia: majority on cholesterol-lowering treatment but a minority reaches treatment goal. PLoS One 2010; 5: e9220.

8. Perez de Isla L, Alonso R, Watts GF, et al. Attainment of LDL-cholesterol treatment goals in patients with familial hypercholesterolemia: 5-Year SAFEHEART registry follow-up. J Am Coll Cardiol 2016; 67: 1278-85.

9. Beliard S, Carreau V, Carrie A, et al. Improvement in LDL-cholesterol levels of patients with familial hypercholesterolemia: can we do better? Analysis of results obtained during the past two decades in 1669 French subjects. Atherosclerosis 2014; 234: 136-41.

10. Bogsrud MP, Graesdal A, Johansen D, et al. LDL-cholesterol goal achievement, cardiovascular disease, and attributed risk of $L p(a)$ in a large cohort of predominantly genetically verified familial hypercholesterolemia. J Clin Lipidol 2019; 13: 279-86.

11. Ray KK, Molemans B, Schoonen WM, et al. EU-wide cross-sectional observational study of lipid-modifying therapy use in secondary and primary care: the DA VINCI study. Eur J Prev Cardiol 2020; 28: 1279-89.

12. Banach M, Stulc T, Dent R, Toth PP. Statin non-adherence and residual cardiovascular risk: there is need for substantial improvement. Int J Cardiol 2016; 225: 184-96.
13. Nikolic D, Banach M, Chianetta R, et al. An overview of statin-induced myopathy and perspectives for the future. Expert Opin Drug Saf 2020; 19: 601-15.

14. Banach M, Rizzo M, Toth PP, et al. Statin intolerance - an attempt at a unified definition. Position paper from an International Lipid Expert Panel. Expert Opin Drug Saf 2015; 14: 935-55.

15. Rosenson RS, Baker S, Banach M, et al. Optimizing cholesterol treatment in patients with muscle complaints. J Am Coll Cardiol 2017; 70: 1290-301.

16. Serban MC, Colantonio LD, Manthripragada AD, et al. Statin intolerance and risk of coronary heart events and all-cause mortality following myocardial infarction. J Am Coll Cardiol 2017; 69: 1386-95.

17. Gaudet D, Lopez-Sendon JL, Averna M, et al. Safety and efficacy of alirocumab in a real-life setting: the ODYSSEY APPRISE study. Eur J Prev Cardiol 2020: doi: 10.1093/ eurjpc/zwaa097.

18. Friedewald WT, Levy RI, Fredrickson DS. Estimation of the concentration of low-density lipoprotein cholesterol in plasma, without use of the preparative ultracentrifuge. Clin Chem 1972; 18: 499-502.

19. NCD Risk Factor Collaboration. Repositioning of the global epicentre of non-optimal cholesterol. Nature 2020; 582: 73-7.

20. Bosworth HB, Ngouyombo B, Liska J, Zullig LL, Atlani C, Beal AC. The importance of cholesterol medication adherence: the need for behavioral change intervention programs. Patient Prefer Adherence 2018; 12: 341-8.

21. Chowdhury R, Khan H, Heydon E, et al. Adherence to cardiovascular therapy: a meta-analysis of prevalence and clinical consequences. Eur Heart J 2013; 34: 2940-8.

22. Khunti K, Danese MD, Kutikova L, et al. Association of a combined measure of adherence and treatment intensity with cardiovascular outcomes in patients with atherosclerosis or other cardiovascular risk factors treated with statins and/or ezetimibe. JAMA Netw Open 2018; 1: e185554.

23. Farnier M, Hovingh GK, Langslet $G$, et al. Long-term safety and efficacy of alirocumab in patients with heterozygous familial hypercholesterolemia: an open-label extension of the ODYSSEY program. Atherosclerosis 2018; 278: 307-14.

24. Guglielmi V, Bellia A, Pecchioli S, et al. Effectiveness of adherence to lipid lowering therapy on LDL-cholesterol in patients with very high cardiovascular risk: a realworld evidence study in primary care. Atherosclerosis 2017; 263: 36-41.

25. Dormuth CR, Patrick AR, Shrank WH, et al. Statin adherence and risk of accidents: a cautionary tale. Circulation 2009; 119: 2051-7.

26. Jones PH, Bays HE, Chaudhari U, et al. Safety of alirocumab (a PCSK9 monoclonal antibody) from 14 randomized trials. Am J Cardiol 2016; 118: 1805-11. 